\title{
Improvement of Diabetic Macular Edema in the Fellow Eye After Monocular Intravitreal Bevacizumab Injection
}

\author{
Hamidreza Torabi ${ }^{*}$ \\ ${ }^{1}$ Baqiyatallah University of Medical Sciences, Tehran, Iran
}

*Corresponding Author: Hamidreza Torabi, M.D., Assistant Professor of Ophthalmology, Baqiyatallah University of Medical Sciences, Tehran, Iran. Tel: +98-21-81263617, Email: dr_hamidrezatorabi@yahoo.com

Received April 4, 2017; Accepted May 17, 2017; Online Published May 31, 2017

\begin{abstract}
Introduction: Because of bilateral involvement in many cases with diabetic macular edema, intravitreal bevacizumab injection perform in both eyes. There are some reports of therapeutic effects in the fellow eye after monocular injection of anti-vascular endothelial growth factors. In this study we describe a case of bilateral improvement of diabetic macular edema following unilateral intravitreal bevacizumab injection.

Case Presentation: We report a patient with bilateral non-proliferative diabetic retinopathy and diabetic macular edema. Central macular thickness was $398 \mu$ in the right eye and $337 \mu$ in the left eye. Two months after intravitreal injection of 1.2 $5 \mathrm{mg}$ bevacizumab in the right eye, significant improvement of diabetic macular edema was happened in both eyes including the left eye without intravitral injection. Central macular thickness was $245 \mu$ in the right eye and $250 \mu$ in the left eye.

Conclusion: Unilateral injection of intravitreal bevacizumab may have therapeutic effects in the fellow untreated eye. Therefore; unilateral injection in bilateral cases may reduce the costs and complications of bilateral injection.

Keywords: Bevacizumab, Macular edema, Diabetic retinopathy, Optical coherence tomography
\end{abstract}

\section{Introduction}

Bevacizumab is a recombinant humanized monoclonal antibody directed against human vascular endothelial growth factor (VEGF). ${ }^{1}$ Recent studies have demonstrated the beneficial effects and safety of anti-VEGFs in the treatment of diabetic macular edema (DME). ${ }^{2,3}$ Bilateral injection of anti-VEGFs is usually performed, because DME frequently presents bilaterally. ${ }^{4}$ There are reports of therapeutic effects in the fellow eye after the monocular injection of anti-VEGFs, including decreased fluorescein leakage in the fellow eye after intravitreal injection of 1.25 mg of bevacizumab in patients with DME. ${ }^{5}$

The current study describes an interesting case of significant improvement of DME in the contralateral eye after the monocular intravitreal injection of bevacizumab.

\section{Case Presentation}

A 54-year-old man with a history of diabetes mellitus type II presented with decreased vision in both eyes. The anterior segment was normal in a slit-lamp examination. Fundoscopy showed bilateral non-proliferative diabetic retinopathy with DME. Optical coherence tomography (OCT) was performed. The central macular thickness was $398 \mu$ OD and $337 \mu$ OS (Figures 1A \& B).

Intravitreal injection of $1.25 \mathrm{mg} / 0.05 \mathrm{~mL}$ bevacizumab was performed in the right eye. Two months later the patient presented for examination, and OCT was done. Surprisingly, significant improvement of DME had occurred in both eyes, including the left eye that had not received intravitreal injection. Central macular thickness was $245 \mu$ in the right eye and $250 \mu$ in the left eye (Figures $2 \mathrm{~A} \& \mathrm{~B})$. The patient was not conferring for further follow up.

\section{Discussion}

Today, the potential effect of unilateral injection of antiVEGFs in the fellow eye is controversial. In a prospective study, Gamulescu and Helbig showed no effects in the fellow eye of 26 eyes with bilateral neovascular age-related
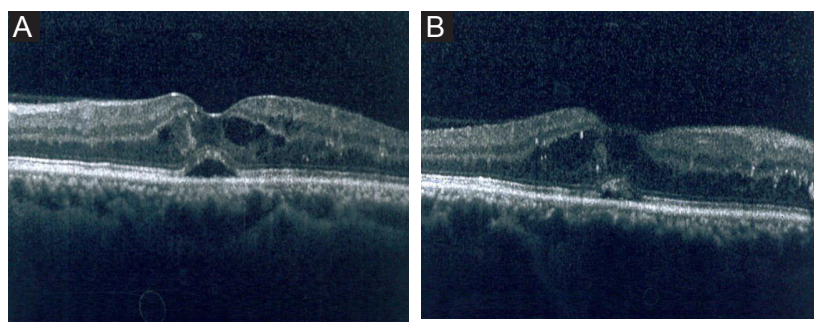

Figure 1. Optical Coherence Tomography of the Right Eye (a) and Left Eye (b) Before Treatment.

Copyright $\odot 2017$ The Hospital Practices and Research. This is an open-access article distributed under the terms of the Creative Commons Attribution License (http://creativecommons.org/licenses/by/4.0), which permits unrestricted use, distribution, and reproduction in any medium, provided the original work is properly cited. 

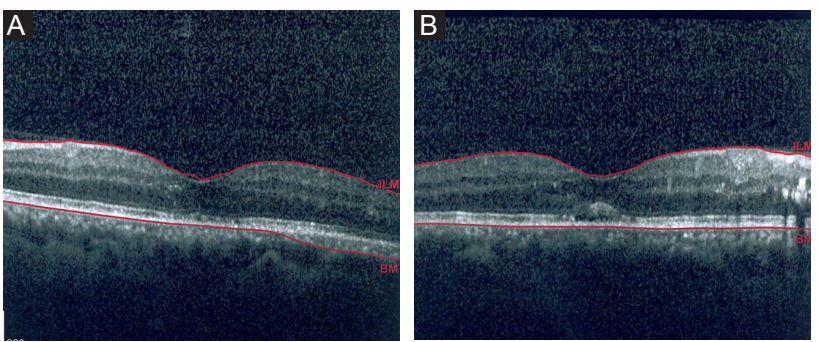

Figure 2. Optical Coherence Tomography of the Right Eye (A) and Left Eye (B) After Intravitreal Injection of $1.25 \mathrm{mg}$ Bevacizumab in the Right Eye.

macular degeneration treated with ranibizumab. ${ }^{6}$ Another study by Velez-Montoya et al showed that unilateral bevacizumab injection in 23 patients with bilateral DME had no effect on the fellow eye.

Several studies have demonstrated the potential effects of unilateral anti-VEGF injection in fellow eye; for example, Hanhart et al reported that unilateral bevacizumab injection in patients with bilateral DME is often associated with bilateral response. ${ }^{4}$ Zlatcavitch et al reported a patient with progression to macula-off tractional retinal detachment in a contralateral eye within 7 days after intravitreal injection of bevacizumab. ${ }^{8} \mathrm{Wu}$ et al described a patient with macular edema due to branch retinal vein occlusion (BRVO) in the right eye and choroidal neovascularization in the left eye. They showed that intravitreal injection of bevacizumab in the right eye resulted in a reduction in macular edema in the left eye and vise versa. ${ }^{9}$

Recent studies have revealed that the anti-VEGF concentration in the fellow eye increased after unilateral injection. The peak concentration of bevacizumab in the aqueous humor of the fellow eye after the unilateral injection of $1.25 \mathrm{mg}$ bevacizumab occurred 7 days after injection ${ }^{10,11}$; about 4 weeks after injection, peak concentration of bevacizumab occurred in the vitreous of the fellow eye. ${ }^{10}$

In this study, we report a patient with bilateral DME in which significant improvement in macular edema was seen after the intravitreal injection of $1.25 \mathrm{mg}$ of bevacizumab in the contralateral eye. Therefore, therapeutic effects of bevacizumab in the fellow eye are possible, and further research is required to document such fellow eye effects. Unilateral injection of anti-VEGFs for bilateral disease, if probable, can lead to a reduction of costs and complications.

\section{Conclusion}

The unilateral injection of intravitreal bevacizumab may have therapeutic effects in the fellow eye and reduce the costs and complications of bilateral injection in patients with bilateral disease.

\section{Conflict of Interest Disclosures}

The author declares that he has no conflicts of interest.

\section{Ethical Approval}

This study was approved by the Ethics Committee of the local hospital.

\section{References}

1. Meyer $\mathrm{CH}$, Krohne TU, Holz FG. Concentrations of unbound bevacizumab in the aqueous of untreated fellow eyes after a single intravitreal injection in humans. Acta Ophthalmol. 2012:90:68-70. doi:10.1111/j.1755-3768.2009.01842.x.

2. Elman MJ, Aiello LP, Beck RW, et al. Randomized trial evaluating ranibizumab plus prompt or deferred laser or triamcinolone plus prompt laser for diabetic macular edema. Ophthalmology. 2010;117(6):1064-1077.e35. doi:10.1016/j. ophtha.2010.02.031.

3. Elman MJ, Bressler NM, Qin H, et al. Expanded 2-year follow-up of ranibizumab plus prompt or deferred laser or triamcinolone plus prompt laser for diabetic macular edema. Ophthalmology. 2011;118(4):609-614. doi:10.1016/j.ophtha.2010.12.033.

4. Hanhart J, Tiosano L, Averbukh E, Banin E, Hemo I, Chowers I. Fellow eye effect of unilateral intravitreal bevacizumab injection in eyes with diabetic macular edema. Eye (Lond). 2014;28(6):646-653. doi:10.1038/eye.2014.94.

5. Avery RL, Pearlman J, Pieramici D, et al. Intravitreal bevacizumab (Avastin) in the treatment of proliferative diabetic retinopathy. Ophthalmology. 2006;113(10):1695-1705. doi:10.1016/j.ophtha.2006.05.064.

6. Gamulescu MA, Helbig H. Lack of therapeutic effect of ranibizumab in fellow eyes after intravitreal administration. J Ocul Pharmacol Ther. 2010;26(2):213-216. doi:10.1089/ jop.2009.0126

7. Velez-Montoya R, Fromow-Guerra J, Burgos O, Landers MB 3rd, Morales-Catón V, Quiroz-Mercado H. The effect of unilateral intravitreal bevacizumab (avastin), in the treatment of diffuse bilateral diabetic macular edema: a pilot study. Retina 2009;29(1):20-26. doi:10.1097/IAE.0b013e318186c64e.

8. Zlotcavitch L, Flynn HW Jr, Avery RL, Rachitskaya A. Progression to macula-off tractional retinal detachment after a contralateral intraoperative intravitreal bevacizumab injection for proliferative diabetic retinopathy. Clin Ophthalmol. 2015:9:69-71. doi:10.2147/OPTH.S69466.

9. Wu Z, Sadda SR. Effects on the contralateral eye after intravitreal bevacizumab and ranibizumab injections: a case report. Ann Acad Med Singapore 2008;37(7):591-3.

10. BakriSJ, SnyderMR, Reid JM, PulidoJS, Singh RJ. Pharmacokinetics of intravitreal bevacizumab (Avastin). Ophthalmology. 2007;114(5):855-859. doi:10.1016/j.ophtha.2007.01.017.

11. Nomoto $\mathrm{H}$, Shiraga $\mathrm{F}$, Kuno $\mathrm{N}$, et al. Pharmacokinetics of bevacizumab after topical, subconjunctival and intravitreal administration in rabbits. Invest Ophthalmol Vis Sci. 2009;50(10):4807-4813. doi:10.1167/iovs.08-3148. 